REPORT

\title{
Defining a role for fibroblasts in the persistence of chronic inflammatory joint disease
}

C D Buckley, A Filer, O Haworth, G Parsonage, M Salmon

Ann Rheum Dis 2004;63(Suppl II):ii92-ii95. doi: 10.1136/ard.2004.028332

The most surprising feature of the inflammatory response in rheumatoid arthritis is not that it occurs but that it does not resolve. The persistence of the chronic inflammatory response in conjunction with ongoing joint destruction is an all too familiar finding in many patients with rheumatoid arthritis. Despite the use of effective anti-inflammatory agents and disease modifying drugs, a significant proportion of patients with rheumatoid arthritis continue to have resistant disease. Complete clinical remission is unusual for more than six months and a formal cure of the disease remains elusive. In this report we focus on how attempts to address the question of why rheumatoid arthritis persists have led to a different interpretation of the pathogenesis of rheumatoid disease; one in which alterations in stromal cells such as fibroblasts play an important role in the switch from resolving to persistent disease.

$\mathrm{R}$ heumatoid arthritis is a systemic disease in which the clinical picture is dominated by synovitis and joint destruction. ${ }^{1}$ The dominant pathological features are hyperplasia of resident synovial stromal cells and heavy infiltration of haematopoietic cells including lymphocytes, granulocytes, and monocytes. ${ }^{2}$ Current models of disease pathogenesis stress the role of antigen specific lymphocyte responses and attempt to address the causative agent. However, recent studies have challenged the primacy of the lymphocyte and have begun to focus on an extended immune system in which stromal cells, such as macrophages and fibroblasts play a role in the persistence of the inflammatory response. $^{3}{ }^{4}$

Epidemiological data support the case for both environmental and genetic factors in the pathogenesis of rheumatoid arthritis. ${ }^{5}$ Studies in twins have shown that the genetic contribution is at best only 30\% implying that there is a substantial contribution from the environment. ${ }^{6}$ An important genetic determinant for rheumatoid arthritis resides within the groove of the human leucocyte antigen (HLA) molecules that bind antigen and present it to T cells (typically the alleles HLA-DR4 and DRI). The fact that these HLA specificities are associated with rheumatoid arthritis does not necessarily imply that self-reactive $\mathrm{T}$ cells elicit or even perpetuate the disease. In fact, recent studies have provided alternative and potentially more exciting explanations for the HLA link with autoimmune diseases such as rheumatoid arthritis. In this model the HLA association does not predispose to disease but rather is associated with a failure to protect from overreactive immune responses ${ }^{7}$ and with a prematurely ageing immune system. ${ }^{8}$ These alternative explanations provide elegant explanations for the puzzling lack of antigen specific $\mathrm{T}$ cell responses in rheumatoid arthritis. ${ }^{9}$
There remain many enigmas about the inflammatory response in rheumatoid arthritis. ${ }^{10}$ First, the pattern of joint involvement is classically symmetrical and involves small joints. Secondly, the disease is more common in females, improves in pregnancy and often relapses post partum. Thirdly, despite tremendous efforts no specific antigenic responses have been found in synovial lymphocytes. Fourthly, in spite of the ongoing inflammatory response in joints, systemic immune responses in rheumatoid arthritis are blunted, and $\mathrm{T}$ cells isolated from the synovial microenvironment display a "frustrated" phenotype (discordance between the expression of markers that normally designate an activated phenotype and actual function). This discrepancy is mirrored in clinical observations where joint destruction and the inflammatory response often appear to be dissociated from each other. ${ }^{11}$ These observations have led to the suggestion that resident stromal cells such as macrophages and fibroblasts, which are not effectively targeted by conventional therapy, also play an important role in disease progression. ${ }^{4}$

\section{FEATURES OF INFLAMMATION: INTERACTIONS BETWEEN HAEMATOPOIETIC AND STROMAL CELLS} Inflammatory responses occur within tissue microenvironments with contributions from both haematopoietic and stromal cells. The inflammatory reaction is a complex process which despite occurring in different tissues nevertheless has a number of generic features in which leucocytes are recruited in response to injury or invading pathogens. ${ }^{12}$ Chronic persistent inflammation is characterised both pathologically, in that the predominant cell types are lymphocytes and macrophages, and temporally, in that the inflammatory response lasts for weeks to years as opposed to days. During the initial phases of an inflammatory response, large numbers of leucocytes are recruited to the injured site in response to changes in the expression of proinflammatory adhesion molecules and chemoattractant cytokines/mediators by the inflamed endothelium. However, it remains unclear why inflammatory responses exhibit clear tissue tropisms, such that-for example, rheumatoid disease localises mainly to the synovium, psoriasis to the skin, multiple sclerosis to the brain and so on. ${ }^{13}$

Inflammation normally resolves via an active process involving naturally occurring anti-inflammatory mediators which gradually replace proinflammatory mediators. Examples of naturally occurring anti-inflammatory mediators include annexin 1 which acts via paracrine and autocrine routes to downregulate the process of leucocyte extravasation into tissues. ${ }^{14}$ Lipoxins are another example of endogenously produced mediators that are involved in inhibiting neutrophil chemotaxis, adhesion, and transmigration, induced by mediators such as leukotrienes (products of arachidonic acid). ${ }^{15}$ While lipoxins inhibit attraction of neutrophils, they are potent chemoattractants for monocytes. This is important for the resolution of inflammation as macrophages remove 


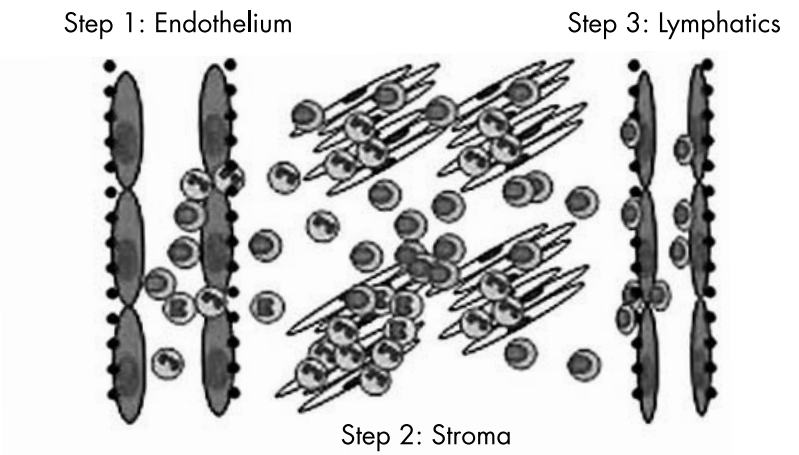

(2) Neutrophil (3) Monocyte

Figure 1 Leucocyte-stromal interactions are involved at every stage in the trafficking of leucocytes into, within, and out of tissues. The molecular basis by which leucocytes leave the circulation and migrate across endothelium has been well studied (step 1, endothelium). How leucocytes interact with stromal cells (step 2) and how they exit tissue into the lymphatics (step 3) remains poorly understood.

apoptotic neutrophils from the inflammatory environment by phagocytosis. ${ }^{14}$ Once inflammatory cells are no longer required, those cells that are in the tissues either exit out of the tissues (via draining lymphatics) or die through the loss of survival signals and initiation of apoptosis (fig 1).

It has been suggested that chronic inflammation may persist as a result of failure of the processes involved in wound healing. ${ }^{16}$ Both inflammation and wound healing are characterised by the formation of new tissue, such as endothelium, smooth muscle, and fibroblasts. Interestingly these new cells are not necessarily derived from adjacent tissue but from bloodborne precursors termed fibrocytes. These cells are defined by markers of both haemopoietic (CD45) and stromal lineages (smooth muscle actin and collagen I), circulate within the blood, and can home to areas of inflammation, where they differentiate into a variety of different stromal cell types. ${ }^{17-19}$ Further credence to the idea that chronic, persistent inflammation is a failure of wound healing comes from the recent finding that fibroblasts can support the expansion of inflammatory $\mathrm{T}$ cells by expressing HLA-DR and thrombospondin, a matrix molecule that is mainly expressed in chronically inflamed and injured tissues. ${ }^{20}$

\section{FIBROBLASTS: KEY CELLS IN THE SWITCH TO PERSISTENT DISEASE}

The response to tissue damage involves a carefully choreographed series of interactions between diverse cellular, humoral, and connective tissue elements. For an inflammatory lesion to resolve, dead or redundant cells that were recruited and expanded during the active phases of the response must be removed. In addition resident stromal cells, largely defined by fibroblasts, attempt to repair damaged tissue. It is becoming increasingly clear that fibroblasts are not passive players in immune responses. ${ }^{21}$ Different fibroblasts secrete distinct patterns of matrix proteins, cytokines, and chemokines, and express variable levels of costimulatory molecules such as CD40 and vascular cell adhesion molecule (VCAM)-1 (CDI06) suggesting a fundamental role in immune responses and disease processes. ${ }^{22}{ }^{23}$ We and others have found that fibroblasts exhibit considerable diversity, topographic differentiation, and retain positional memory even when cultured in vitro (fig 2). Furthermore the transcriptional profile of fibroblasts can be significantly modified by stimulation with either $\mathrm{T}$ helper (Th) 1 (interferon $\gamma$ ) or

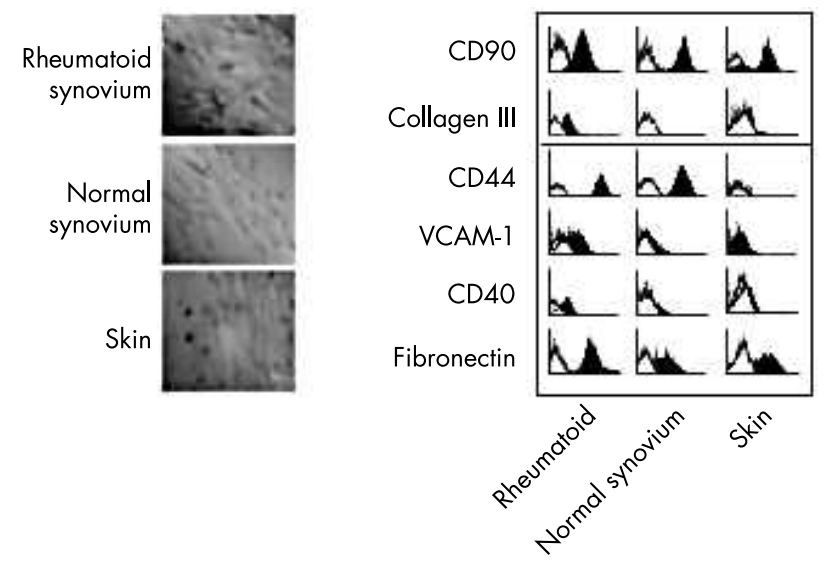

Figure 2 Not all fibroblasts are the same. Fibroblasts from the rheumatoid, or normal synovium look different from fibroblasts from the skin and express different patterns of adhesion and matrix molecules compared with fibroblasts derived from the skin. Pictures (left) show fibroblasts labelled for fibronectin with nuclei counter stain. A range of markers (CD90, collagen III, CD44, VCAM-1 (CD106), CD40, and fibronectin) have been used to label either rheumatoid, normal synovium, or skin fibroblasts which have then been examined by flow cytometry.

Th2 cytokines (interleukin-4) such that fibroblasts from peripheral tissue (synovium and skin) can be made to express genes more characteristic of lymphoid tissue (lymph node and tonsil). ${ }^{24}$

Fibroblasts are extremely versatile connective tissue cells displaying a remarkable capacity to differentiate into other members of the connective tissue family including cartilage, bone, adipocyte, and smooth muscle cells. ${ }^{25}{ }^{26}$ Fibroblasts from different anatomical regions display characteristic phenotypes that are maintained even after prolonged culture in vitro, suggesting that many fibroblasts have an imprinted phenotype that is remarkably stable. ${ }^{27}{ }^{28}$ Even within a single tissue there is growing evidence that fibroblasts are not a homogeneous population, but exist as subsets of cells, much like tissue macrophages and dendritic cells. ${ }^{29}$ It is likely that connective tissue contains a mixture of distinct fibroblast lineages with mature fibroblasts existing side by side with immature fibroblasts (often called mesenchymal fibroblasts) that are capable of differentiating into other connective tissue cells. ${ }^{25}$ Tantalising evidence now suggests that fibroblast precursors circulate in peripheral blood..$^{30}$ These cells share many properties of bone marrow stromal stem cells and are capable of differentiating into several cell lineages. ${ }^{31}{ }^{32}$ This diversity in phenotype and function that characterises fibroblasts from different anatomical sites may play a significant role in the intrinsic susceptibility of different organs to inflammatory insults. It may also provide the molecular basis for the well described but as yet poorly understood clinical finding that relapses in chronic inflammation are often tissue and site specific.

There is now a large body of evidence to support the role of synovial fibroblasts in defining the abnormal microenvironment that characterises the rheumatoid synovium. ${ }^{334}$ Synovial inflammation appears to persist in rheumatoid arthritis because of disordered fibroblast behaviour in which a failure to switch off their inflammatory programme leads to the inappropriate accumulation of leucocytes within the inflamed synovium. Current studies are addressing whether the point at which the synovial microenvironment "commits" to becoming able to sustain an inflammatory infiltrate can be identified clinically. If such a point of commitment does exist then a therapeutic window for therapy may be 
available to prevent the switch to a chronic persistent phenotype. If this commitment point already exists at the time of first presentation with synovitis then alternative strategies aimed at "resetting" the synovial microenvironment to encourage resolution will need to be developed. Recent findings therefore suggest that targeting the stromal microenvironment in general and tissue fibroblasts in particular is likely to be an important target for future antiinflammatory therapy.

\section{WHAT DETERMINES THE NATURE AND NUMBER OF LEUCOCYTES THAT ACCUMULATE WITHIN TISSUES: A ROLE FOR STROMAL SELECTION?}

The maintenance of a persistent leucocyte infiltrate at sites of chronic inflammation reflects a distorted balance between those factors that enhance cellularity (leucocyte recruitment, proliferation, and retention) and those that decrease cellularity (cell death and emigration) (fig 3). While the mechanisms responsible for the recruitment of leucocytes into and their proliferation within tissues have been well studied, those responsible for their survival, retention, and emigration have attracted much less attention.

The successful resolution of an inflammatory response requires the removal of the vast majority of immune cells that were recruited and expanded during the active phase of the response. A number of studies have shown that during the resolution phase of viral infections, the initial increase in $\mathrm{T}$ cell numbers in peripheral blood, seen within the first few days is followed by a wave of apoptosis occurring in the activated T cells. This situation is mirrored within tissues, where Fas induced apoptosis occurs at the peak of the inflammatory response and may be responsible for limiting the extent of the immune response. In contrast the resolution phase appears to be principally triggered by cytokine deprivation induced apoptosis. ${ }^{35}$ In rheumatoid arthritis this resolution phase becomes disordered. Recent studies have shown that a failure of synovial $\mathrm{T}$ cells to undergo apoptosis or programmed cell death contributes to the persistence of the inflammatory infiltrate. The survival pathway shares all the essential hallmarks of a stromal cell, cytokine mediated mechanism (high Bcl- $\mathrm{X}_{\mathrm{L}}$, low Bcl-2, and lack of cell proliferation). We have identified type I interferons, produced by synovial fibroblasts and macrophages, as the principal factors responsible for prolonged $\mathrm{T}$ cell survival in the rheumatoid joint. ${ }^{36}$ It is likely that such a mechanism occurs in many chronic inflammatory conditions in which
Acute resolving inflammation

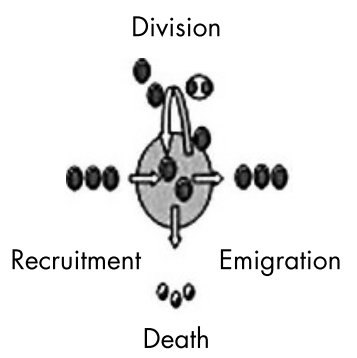

Chronic persistent inflammation

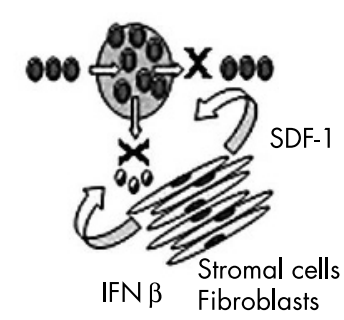

Figure 3 The dynamics of the synovial inflammatory infiltrate. The dynamic balance of cells in any tissue compartment depends on the balance of cells that enter, exit, proliferate, or die. Homoeostasis is maintained during normal inflammatory responses leading to resolution of the inflammatory infiltrate. In chronic persistent inflammation inappropriate accumulation of leucocytes is caused by stromal production of prosurvival (interferon $\beta$ ) and proretentive (stromal cell derived factor 1 (SDF-1); CXCL12) factors by fibroblasts and other resident tissue stromal cells.
$\mathrm{T}$ cells accumulate. Interestingly while type I interferon has been shown to be beneficial in multiple sclerosis (a disease in which tissue scarring and not heavy $\mathrm{T}$ cell infiltrates are observed) these results predict that type I interferon may make rheumatoid arthritis worse. The reverse holds true for the use of antitumour necrosis factor (anti-TNF) therapy in rheumatoid arthritis and multiple sclerosis.

While the inhibition of $\mathrm{T}$ cell apoptosis by stromal cells at sites of chronic inflammation contributes to T cell accumulation, it is unlikely to be the only mechanism, because these cells should be able to leave the joint during the resolution of inflammation, even if their death is inhibited. A number of studies have reported that the synovial microenvironment contributes directly to the inappropriate retention of $\mathrm{T}$ cells within the joint, by an active chemokine dependent process requiring the production of SDF-1 (CXCL12) by stromal cells and the expression of its receptor CXCR4 on infiltrating $\mathrm{T}$ cells. ${ }^{37}$ Chemokines are important molecular "signposts" that direct leucocyte trafficking and positioning within tissues. Their inappropriate production and expression can lead to the wrong type of leucocytes accumulating in the wrong tissues at the wrong time. It seems that the ectopic expression of chemokines appears to be a general characteristic of a number of chronic rheumatic conditions since another B cell attracting chemokine BCA-1(CXCL13) is inappropriately expressed by stromal cells in the salivary glands of patients with Sjögren's syndrome. ${ }^{38}$ This finding provides an exciting potential molecular link between infection, inflammation, and cancer since BCA-1 has been shown to be upregulated by Helicobacter pylori infection and involved in the pathogenesis of some lymphomas. ${ }^{39}$ Thus in chronic inflammation the inflammatory infiltrate appears to persist as a direct result of the sustained recruitment, inappropriate retention, and enhanced survival of cells-a process that is mediated by stromal factors associated with the local microenvironment itself. Exciting new therapies based on promoting $\mathrm{T}$ cell apoptosis and neutralising chemokines that lie downstream of TNF signalling pathways are currently being assessed in animal models of arthritis.

\section{CONCLUSIONS}

The prevailing paradigm accounting for the accumulation of specific leucocyte subsets in an inflamed tissue is based upon endothelial selectivity at the point of recruitment, a process in which chemokines are intimately involved. However, this ignores the potential for selection occurring within the tissue, mediated by stromal elements which play well documented roles in lymphocyte selection in the bone marrow and thymus. The molecular basis for site specific inflammatory responses remains obscure, but there is now accumulating evidence that fibroblasts are responsible for directing the site specificity of inflammation. The stromal microenvironment may imprint a stromal postcode (analogous to the endothelial area postcode involved in leucocyte recruitment into tissue) on inflammatory leucocytes which governs their retention or subsequent return to that specific location. In this way stromal cells might direct the location of an inflammatory response, in addition to perpetuating that inflammation in persistent inflammatory diseases.

\section{Authors' affiliations \\ C D Buckley, A Filer, O Haworth, G Parsonage, M Salmon,}

Rheumatology Research Group, Division of Immunity and Infection, Institute of Biomedical Research, MRC Center for Immune Regulation, University of Birmingham, Birmingham, UK

Correspondence to: CD Buckley, Department of Rheumatology, Division of Immunity and Infection, University of Birmingham, Birmingham, B15 2TT, UK; c.d.buckley@bham.ac.uk 


\section{REFERENCES}

1 Firestein GS. Evolving concepts of rheumatoid arthritis. Nature 2002;423:356-61.

2 Buckley CD. Science, medicine, and the future. Treatment of rheumatoid arthritis. BMJ 1997;315:236-8.

3 Firestein GS. Invasive fibroblast-like synoviocytes in rheumatoid arthritis. Passive responders or transformed aggressors? Arthritis Rheum 1996;39:1781-90.

4 Buckley CD, Pilling D, Lord JM, Akbar AN, Scheel-Toellner D, Salmon M. Fibroblasts regulate the switch from acute resolving to chronic persistent inflammation. Trends Immunol $2001 ; 22: 199-204$.

5 Dooley MA, Hogan SL. Environmental epidemiology and risk factors for autoimmune disease. Curr Opin Rheumatol 2003;15:99-103.

6 Silman AJ. Do genes or environment influence development of rheumatoid arthritis? BMJ 2002;324:264

7 Zanelli E, Breedveld FC, de Vries RR. HLA association with autoimmune disease: a failure to protect? Rheumatology 2000;39:1060-6.

8 Salmon M, Akbar AN. Telomere erosion: a new link between HLA DR4 and rheumatoid arthritis. Trends Immunol 2004;25:339-41.

9 Vallejo AN, Weyand CM, Gronzy JJ. T cell senescence: a culprit of immune abnormalities in chronic inflammation and persistent infection. Trends $\mathrm{Mol}$ Med 2004; 10:119-24

10 Smolen JS, Steiner G. Therapeutic strategies for rheumatoid arthritis. Nat Rev Drug Discov 2003;2:473-88.

11 Muller-Ladner U, Gay RE, Gay S. Cellular pathways of joint destruction. Curr Opin Rheumatol 1997;9:213-20.

12 Cavender $D$, et al. Pathways to chronic inflammation in rheumatoid synovitis. Fed Proc 1987;46:113-17.

13 Douglas MR, Morrison KE, Salmon M, Buckley CD. Why does chronic inflammation persist: a dominant role for the stromal microenvironment? Exp Rev Mol Med 9 December, www.expertreviews.org/02005264h.htm.

14 Gilroy DW, Lawrence T, Perretti M, Rossi AG. Inflammatory resolution: new opportunities for drug discovery. Nat Rev Drug Discov 2004;3:401-16.

15 Brady HR, Lamas S, Papayianni A, Takata S, Matsubara M, Marsden PA Lipoxygenase product formation and cell adhesion during neutrophilglomerular endothelial cell interaction. Am J Physiol 1995;268:F1-F12.

16 Majno G. Chronic inflammation: links with angiogenesis and wound healing Am J Pathol 1998;153:1035-9.

17 Abe R, Donnelly SC, Peng T, Bucala R, Metz CN. Peripheral blood fibrocytes: differentiation pathway and migration to wound sites. J Immunol $2001 ; 166: 7556-62$

18 Jones EA, Kinsey SE, English A, Jones RA, Straszynski L, Meredith DM, et al. Isolation and characterization of bone marrow multipotential mesenchymal progenitor cells. Arthritis Rheum 2002;46:3349-60.

19 Pittenger MF, Mackay AM, Beck SC, Jaiswal RK, Douglas R, Mosca JD, et al. Multilineage potential of adult human mesenchymal stem cells. Science 1999;284: 143-7

20 Vallejo AN, Yang H, Klimiuk PA, Weyand CM, Goronzy JJ. Synoviocytemediated expansion of inflammatory T cells in rheumatoid synovitis is dependent on CD47-thrombospondin 1 interaction. J Immunol 2003;171:1732-40

21 Pap T, Muller-Ladner U, Gay RE, Gay S. Fibroblast biology: role of synovial fibroblasts in the pathogenesis of rheumatoid arthritis. Arthritis Res 2000;2:361-7.
22 Buckley CD. Michael Mason prize essay 2003. Why do leucocytes accumulate within chronically inflamed joints? Rheumatology 2003:42:1433-44

23 Brouty-Boye D, Pottin-Clemenceau C, Doucet C, Jasmin C, Azzarone B. Chemokines and CD40 expression in human fibroblasts. Eur J Immunol 2000;30:914-19.

24 Parsonage G, Falciani F, Burman A, Filer A, Ross E, Bofill M, et al. Global gene expression profiles in fibroblasts from synovial, skin and lymphoid tissue reveals distinct cytokine and chemokine expression patterns. Thromb Haemost 2003;90:688-97.

25 Harris J. In: Alberts B, Bray D, Lewis J, Raff M, Roberts K, Watson JD. Molecular Biology of the Cell, 3rd edn. New York: Garland Press, 1994:1139-93.

26 Vaday GG, Lider O. Extracellular matrix moieties, cytokines, and enzymes: dynamic effects on immune cell behavior and inflammation. J Leukoc Biol 2000;67:149-59.

27 Hogaboam CM, Steinhauser ML, Chensue SW, Kunkel SL. Novel roles for chemokines and fibroblasts in interstitial fibrosis. Kidney Int 1998:54:2152-9.

28 Smith RS, Smith TJ, Blieden TM, Phipps RP. Fibroblasts as sentinel cells. Synthesis of chemokines and regulation of inflammation. Am J Pathol 1997; 151:317-22.

29 Marinova-Mutafchieva L, Taylor P, Funa K, Maini RN, Zvaifler NJ. Mesenchymal cells expressing bone morphogenetic protein receptors are present in the rheumatoid arthritis joint. Arthritis Rheum 2000;43:2046-55.

30 Zvaifler NJ, Marinova-Mutafchieva L, Adams G, Edwards CJ, Moss J, Burger JA, et al. Mesenchymal precursor cells in the blood of normal individuals. Arthritis Res 2000;2:477-88.

31 Bianco P, Robey PG. Marrow stromal stem cells. J Clin Invest 2000;105:1663-8.

32 Whetton AD, Graham GJ. Homing and mobilization in the stem cell niche. Trends Cell Biol 1999;9:233-8.

33 Akbar AN, Salmon M. Cellular environments and apoptosis: tissue microenvironments control activated T-cell death. Immunol Today 1997; 18:72-6.

34 Zvaifler NJ, Firestein GS. Pannus and pannocytes. Alternative models of joint destruction in rheumatoid arthritis. Arthritis Rheum 1994;37:783-9.

35 Salmon M, Scheel-Toellner D, Huissoon AP, Pilling D, Shamsadeen N, Hyde H, et al. Inhibition of T cell apoptosis in the rheumatoid synovium. J Clin Invest 1997;99:439-46.

36 Pilling D, Akbar AN, Girdlestone J, Orteu CH, Borthwick NJ, Amft N, et al. Interferon-beta mediates stromal cell rescue of $\mathrm{T}$ cells from apoptosis. Eur J Immunol 1999;29:1041-50.

37 Buckley CD, Amft N, Bradfield PF, Pilling D, Ross E, Arenzana-Seisdedos F, et al. Persistent induction of the chemokine receptor CXCR4 by TGF-beta 1 on synovial T cells contributes to their accumulation within the rheumatoid synovium. J Immunol 2000;165:3423-9.

38 Amft N, Curnow SJ, Scheel-Toellner D, Devadas A, Oates J, Crocker J, et al. Ectopic expression of the B cell attracting chemokine BCA-1 (CXCL13) on endothelial cells and within lymphoid follicles contributes to the establishment of germinal center-like structures in Sï̈gren's Syndrome. Arthritis Rheum 2001:44:2633-41.

39 Mazzucchelli L, Blaser A, Kappeler A, Scharli P, Laissue JA, Baggiolini M, et al. BCA-1 is highly expressed in Helicobacter pylori-induced mucosaassociated lymphoid tissue and gastric lymphoma. J Clin Invest 1999:194:R49-R54. 